\title{
Neuroprotective effect of CPCGI on Alzheimer's disease and its mechanism
}

\author{
XIAOPENG WANG and JING ZHAO
}

\begin{abstract}
Department of Neurology, The Second Hospital of Hebei Medical University, Shijiazhuang, Hebei 050000, P.R. China
\end{abstract}
Received March 10, 2019; Accepted September 19, 2019

DOI: $10.3892 / \mathrm{mmr} .2019 .10835$

\begin{abstract}
Alzheimer's disease (AD) is a multifactorial neurodegenerative disorder causing progressive memory loss and cognitive impairment. The aberrant accumulation of amyloid- $\beta$ $(\mathrm{A} \beta)$ and neuroinflammation are two major events in $\mathrm{AD}$. $\mathrm{A} \beta$-induced neurotoxicity and oxidative stress are also involved in the pathogenesis of AD. The purpose of the current study was to investigate the effect of compound porcine cerebroside and ganglioside injection (CPCGI) on the progression of $\mathrm{AD}$, and to explore the molecular mechanism. In vivo and in vitro models of AD were established and treated with CPCGI. A $\beta 40$ and A $\beta 42$ protein levels were detected using western blotting. Production of pro-inflammatory factors [tumor necrosis factor (TNF)- $\alpha$ and interleukin (IL)-1 $\beta$ ] and oxidative stress markers [malondialdehyde (MDA), superoxide dismutase (SOD)] and reactive oxygen species (ROS) production were determined. Cell viability and apoptosis were detected using 3-(4,5-dimethyl-2-thiazolyl)-2,5diphenyl-2-H-tetrazolium bromide assay and flow cytometry analysis respectively. Results demonstrated that CPCGI administration reduced $A \beta 40$ and $A \beta 42$ accumulation, and inhibited inflammatory response and oxidative stress in the in vivo rat model of $A D$, evidenced by decreased $A \beta 40$ and $A \beta 42$ protein expression, reduced levels of TNF- $\alpha$ and IL-1 $\beta$, reduced MDA content, enhanced SOD activity, and reduced ROS level. It was found that CPCGI enhanced cell viability and reduced cell apoptosis of A $\beta 25-35$ induced PC12 cells. In addition, the mitogen-activated protein kinase/NF- $\kappa \mathrm{B}$ pathway was involved in the protective effect of CPCGI on AD. Taken together, the data demonstrated that CPCGI exerted a protective effect on AD by reducing $A \beta$ accumulation, inhibiting inflammatory response and oxidative stress, In addition to preventing neuronal apoptosis.
\end{abstract}

Correspondence to: Dr Xiaopeng Wang, Department of Neurology, The Second Hospital of Hebei Medical University, 215 Hepingxi Road, Shijiazhuang, Hebei 050000, P.R. China E-mail: wangxp190310@163.com

Key words: Alzheimer's disease, compound porcine cerebroside and ganglioside injection, Alzheimer's disease rat model, Alzheimer's disease PC12 cell model

\section{Introduction}

Few subjects in biomedicine have attracted the interest of the scientific and lay communities alike as has Alzheimer's disease. With the sharp rise in life expectancy during the 20th century, more and more old people from $\sim 49$ to $>76$ years suffer from neurodegenerative disorders in the United States (1-3). Among them, AD appears as the most common form of mental failure in old age (4). The main symptoms of $\mathrm{AD}$ are progressive memory disorder, cognitive dysfunction, personality change and language disorder, which seriously affect social, professional and life functions (5). Amyloid $\beta$ (A $\beta$ ) initiates inflammatory reaction in the early stage of disease (6-8). This pathological change can promote the increase of $A \beta$ production and abnormal accumulation, and form cascade amplification effect, resulting in the decrease of neurons and abnormality and causing $\mathrm{AD}$. In addition, $\mathrm{A} \beta$ induced neurotoxicity and oxidative stress also participate in the pathogenesis of $\mathrm{AD}(9)$. Therefore, the pathogenesis of $\mathrm{AD}$ must be understood as soon as possible and corresponding measures taken to prevent and treat it.

Compound porcine cerebroside and ganglioside injection (CPCGI) is a compound preparation, which is used to treat brain dysfunction clinically. It is estimated that each ml of CPCGI contains $0.24 \mathrm{mg}$ monosialotetrahexosyl ganglioside (GM-1), $3.2 \mathrm{mg}$ of polypeptides and $0.125 \mathrm{mg}$ of hypoxanthine $(10,11)$. Hypoxanthine is an important substance in human life, which can improve the metabolism of substance and energy, accelerate the repair of damaged tissue, and restore normal physiological function of anoxic tissue (12). Hypoxanthine, small polypeptide, and amino acid coordination can promote the metabolism of the body. CPCGI has been widely used in China. In clinical studies, CPCGI can significantly shorten the time of fracture healing and promote the curative effect of fracture healing (13). In addition, CPCGI has a significant effect in treating hypoxic ischemic encephalopathy, where it helps to improve the recovery of consciousness and muscle strength, and there is no obvious adverse reaction during the treatment $(11,14)$. A previous study demonstrated that CPCGI could also activate mitochondrial autophagy to improve cerebral ischemia reperfusion injury (10). A clinical study demonstrated that CPCGI can promote the metabolism of brain tissue, participate in the growth, differentiation and regeneration of neurons in brain tissue, and improve the function of cerebral blood circulation and brain metabolism (15). 
However, the effect of CPCGI on AD has not been studied so far. Therefore, the present study investigated the effect of $\mathrm{CPCGI}$ on the progress of $\mathrm{AD}$ in vivo and in vitro and explored its molecular mechanism.

\section{Materials and methods}

Establishment of $A D$ rat model. A total of 40 Wistar rats were selected (age, 10-11 weeks; weight, 240-260 g) from the laboratory animal room of Liaoning University of Traditional Chinese Medicine. The rats fed and drank freely at room temperature $\left(20-22^{\circ} \mathrm{C}\right)$ with $40-50 \%$ humidity, and were maintained under a 12-h light/dark cycle. The present study was performed according to the principles and procedures of the National Institutes of Health's Guide for the Care and Use of Laboratory Animals (16). This study was approved by the Animal Care and Use Committee of the Second Hospital of Hebei Medical University.

The rat model of AD was established using A $\beta 1-42$ (Sigma-Aldrich; Merck KGaA) as in previous studies (17-19). The Wistar male rats were randomly divided into 4 groups with 10 rats in each group: Sham, model, model + vehicle (saline) and model + CPCGI $(1 \mathrm{ml} / \mathrm{kg} / \mathrm{d})$. Rats in the sham group were treated with saline by a gradual intracerebroventricular (icv) injection $(1 \mu \mathrm{l} / \mathrm{min})$ into the lateral ventricle. Rats in the model group were treated with $\mathrm{A} \beta 1-42(400 \mathrm{pmol} / 3 \mu \mathrm{l} / \mathrm{rat})$ by gradual intracerebroventricular (icv) injection ( $1 \mu \mathrm{l} / \mathrm{min}$ ) into the lateral ventricle (17). The $\mathrm{AD}$ model rats received CPCGI treatment $(1 \mathrm{ml} / \mathrm{kg} / \mathrm{d}$; intraperitoneal injection) for 15 consecutive days starting $1 \mathrm{~h}$ after $\mathrm{AD}$ induction. Rats in the model + vehicle group received an equal amount of saline. At the end of the experiment, the rats were anaesthetized with pentobarbital (40 $\mathrm{mg} / \mathrm{kg}$, intraperitoneal injection) before being sacrificed through cervical dislocation (rats without a heartbeat that were not breathing were confirmed as dead). Subsequently, the hippocampal tissues of rats from the different groups were collected. No rats died during the experiment. Tests were terminated when the rats lost more than $15 \%$ of their body weight and every effort was made to alleviate their suffering.

Sucrose preference test. On day 12 after CPCGI treatment, to assess anhedonic behavior of rats, the sucrose preference test was performed as in a previous study (17). Briefly, rats were acclimated to the two-bottle choice paradigm (two identical bottles were placed on the cages) for three days. In order to avoid withdrawal symptoms in rats, each rat was given two bottles, one containing a $2 \%$ sucrose solution and the other containing tap water. The two bottles were changed every $12 \mathrm{~h}$ to avoid a 'side' bias. The amount of the sucrose solution or tap water consumed was detected by weighing the bottles immediately before and after the test. The sucrose preference ratio was calculated as following: Sucrose preference value $(\%)=$ sucrose intake (g) x100\%/[sucrose intake (g) + water intake (g)].

Tail suspension test. Following the final CPCGI treatment, the tail suspension test was performed as previously described (17). In brief, every rat was individually suspended by the tail using a clamp, 3-4 cm from the end, in a gray wooden enclosure $(60 \times 30 \times 20 \mathrm{~cm})$. A square platform was placed under the rat's forepaws and lightly touching them to avoid hemodynamic stress and limb pain. The immobility time was recorded (in seconds) during the 5-min test period.

PC12 AD cell model establishment and treatment. Rat adrenal pheochromocytoma (PC12) cells were purchased from American Type Culture Collection (ATCC, cat. no. CRL-1721). CPCGI was obtained from Jilin Buchang Pharmaceutical Co., Ltd. DMEM high-sugar medium, horse serum, and fetal bovine serum were purchased from Gibco (Thermo Fisher Scientific, Inc.).

PC12 cells were cultured in DMEM containing $10 \%$ fetal bovine serum and $5 \%$ horse serum, and cultured at $37^{\circ} \mathrm{C}$ with $95 \%$ humidity and $5 \% \mathrm{CO}_{2}(20)$. $\mathrm{PC} 12$ cells were divided into control, model, model + vehicle (PBS) and model + CPCGI. In the model + vehicle and model + CPCGI groups, PC12 cells were pre-treated with PBS and CPCGI separately for $1 \mathrm{~h}$ before stimulation with $50 \mu \mathrm{M}$ A $\beta 25-35$ (Sigma-Aldrich; Merck $\mathrm{KGaA}$ ) for $24 \mathrm{~h}$. PC12 cells in the model group were stimulate with $50 \mu \mathrm{M} \mathrm{A} 325-35$ for $24 \mathrm{~h}$ (21). Cells in the control group were not subjected to any treatment. Subsequently, PC12 cells in each group were subjected to the following experiments.

Reverse transcription-quantitative (RT-q) PCR. Total RNA from tissues $(100 \mathrm{mg})$ was collected by using TRIzol ${ }^{\circledR}$ reagent (Thermo Fisher Scientific, Inc.) and reverse transcribed into cDNA using PrimeScript RT Reagent Kit (Takara Bio, Inc.) according to the manufacturer's protocols. The temperature protocol for the reverse transcription reaction was $25^{\circ} \mathrm{C}$ for $5 \mathrm{~min}, 42^{\circ} \mathrm{C}$ for $60 \mathrm{~min}$ and $80^{\circ} \mathrm{C}$ for $2 \mathrm{~min}$. qPCR was performed to analyze gene expression using the cDNA the SYBR RT-PCR kit (Takara Bio, Inc.) according to the manufacturer's protocols. The thermocycling conditions were as follows: $95^{\circ} \mathrm{C}$ for $5 \mathrm{~min}$, followed by 38 cycles of denaturation at $95^{\circ} \mathrm{C}$ for $15 \mathrm{sec}$ and annealing/elongation at $60^{\circ} \mathrm{C}$ for $30 \mathrm{sec}$. Primer sequences were: GAPDH, forward 5'-CTTTGGTAT CGTGGA AGGACTC-3'; reverse 5'-GTAGAGGCAGGG ATGATGTTCT-3'; A $\beta 42$, forward 5'-ATGGCGAGCAAA GTCTCGATC-3'; reverse 5'-CGCAATCACCACGCCGCC CAC-3'. GAPDH was used as the internal control, and the gene expression was quantified by the $2^{-\Delta \Delta C q}$ method (22).

Western blot analysis. Protein expression was detected using western blotting. Radioimmunoprecipitation assay buffer (Auragene Bioscience) was used to extract the proteins from hippocampus or PC12 cells. A bicinchoninic acid protein quantitative kit (Thermo Fisher Scientific, Inc.) was used to detect protein concentrations in line with the manufacturer's instructions. 10\% SDS-PAGE gel electrophoresis was used to isolate proteins ( $30 \mu \mathrm{g} / \mathrm{lane}$ ), and then the proteins were transferred onto PVDF membranes (EMD Millipore). 5\% skimmed milk was used to block the membrane at room temperature for $1 \mathrm{~h}$, and then the membranes were incubated with primary antibodies: $\beta$-Amyloid (for $A \beta 42$ and $A \beta 40$ detection; cat no. 8243; 1:1,000; Cell Signaling Technology, Inc.), Bcl-2 (cat no. ab196495; 1:1,000; Abcam), Bax (cat no. ab32503; 1:1,000; Abcam), cleaved caspase3 (cat no. ab49822; 1:1,000; Abcam), pro-caspase3 (cat no. ab183179; 1:1,000; Abcam), phosphorylated (p)-p38 (cat no. ab4822; 1:1,000; Abcam), p38 (cat no. ab170099; 1:1,000; Abcam), p65 (cat no. ab16502; 1:1,000; Abcam), p-p65 (cat no. ab86299; 1:1,000; Abcam), and $\beta$-actin 

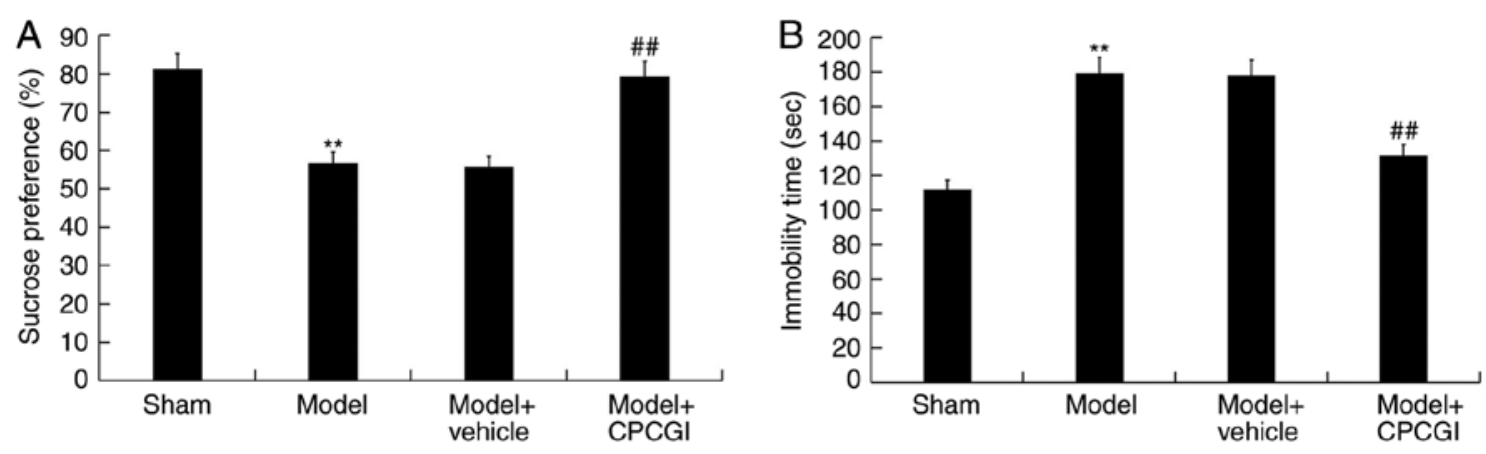

Figure 1. Effects of CPCGI on AD-associated symptoms of rats induced by A $\beta 1-42$. (A) sucrose preference test and (B) tail suspension test. Experiments were repeated three times. Data are given as the mean \pm standard deviation. ${ }^{* *} \mathrm{P}<0.01 \mathrm{vs}$. the sham group; ${ }^{\# \#} \mathrm{P}<0.01 \mathrm{vs}$. the model group. CPCGI, compound porcine cerebroside and ganglioside injection; $\mathrm{AD}$, Alzheimer's disease; $\mathrm{A} \beta$, amyloid- $\beta$.

(cat no. ab179467; 1:1,000; Abcam) at room temperature for 3 h. Subsequently, the PVDF membranes were hybridized with horseradish peroxidase-conjugated anti-rabbit IgG secondary antibody (cat. no. 7074; 1:2,000; Cell Signaling Technology, Inc.) for $1 \mathrm{~h}$. Finally, ECL reagent (Applygen Technologies, Inc.) was used to visualize protein bands. The band density was semi-quantified with Gel-Pro Analyzer densitometry software (version 6.3, Media Cybernetics, Inc.).

Enzyme linked immunosorbent assay (ELISA). The expression of TNF- $\alpha$ (cat. no. PT516) and IL-1 $\beta$ (cat. no. PI303) in the hippocampus of rats from different groups were detected using ELISA kits (Beyotime Institute of Biotechnology) according to the manufacturer's instructions.

SOD activity and MDA content measurement. To determine SOD activity (cat. no. S0101) and MDA content (cat. no. S0131) in the hippocampus of rats, commercial colorimetric detection kits (Beyotime Institute of Biotechnology) were performed following the manufacturer's instructions.

Reactive oxygen species (ROS) production detection. A Reactive Oxygen Species Assay kit (cat. no. S0033, Beyotime Institute of Biotechnology) was used to determine the production of ROS in the hippocampus of rats according to the manufacturer's instructions. The ROS level was expressed as the percentage of the dichlorofluorescein (DCF) fluorescence level in control group whose DCF level was set to $100 \%$.

Cell viability analysis. Cell viability was determined by the conventional MTT assay. Following treatment, PC12 cells were seeded in 96 -well plates $\left(10^{4}\right.$ cells/well $)$ and incubated at $37^{\circ} \mathrm{C}$ for $24 \mathrm{~h}$. Then MTT solution $(10 \mu \mathrm{l})$ was added to each well and the cells were incubated for further $4 \mathrm{~h}$ at $37^{\circ} \mathrm{C}$. Subsequently, $100 \mu 1$ DMSO (Nanjing KeyGen Biotech Co., Ltd.) was used to dissolve the formazan crystals. Finally, the absorbance was measured at the wavelength of $490 \mathrm{~nm}$ by using a micro-plate reader (Synergy2, BioTek Instruments, Inc.).

Apoptosis assay. Flow cytometry (BD Accuri Flow Cytometer, BD Biosciences) was performed to analyze cell apoptosis. PC12 cells were treated with or without CPCGI for $48 \mathrm{~h}$. Then, the cell apoptosis was determined by using the Annexin V-fluorescein isothiocyanate/propidium iodide apoptosis detection kit [cat. no. 70-AP101-100; Multisciences (Lianke) Biotech Co., Ltd.] in accordance with the manufacturer's protocols. FlowJo 7.6 software (FlowJo LLC) was used to analyze the cell apoptosis rate.

Statistical analysis. Statistical analysis was performed using SPSS 18.0 (SPSS, Inc.). All experiments were performed three times. Data are presented as mean \pm standard deviation. The differences between groups were analyzed by one-way analysis of variance with Tukey's post hoc test. $\mathrm{P}<0.05$ was considered to indicate a statistically significant difference.

\section{Results}

CPCGI ameliorates AD-associated symptoms of rats induced by $A \beta 1-42$. To study the therapeutic effect of CPCGI on $\mathrm{AD}$, the rat model of $\mathrm{AD}$ was constructed and then treated with CPCGI. It was found that the reduced the percentage of sucrose preference of rats induced by A $\beta 1-42$ was significantly increased by CPCGI treatment (Fig. 1A). The enhanced immobility time of rats caused by $\mathrm{A} \beta 1-42$ administration was significantly reduced by CPCGI treatment (Fig. 1B).

CPCGI treatment inhibited inflammatory response and oxidative stress in AD model rats induced by A $\beta 1-42$. Results suggested that compared with sham group, the protein expression of $A \beta 40$ and $A \beta 42$ in the hippocampus of $A D$ model rats was markedly increased, while CPCGI significantly decreased the expression of $A \beta 40$ and $A \beta 42$ (Fig. 2A). Compared with the sham group, the mRNA expression of $A \beta 40$ and $A \beta 42$ in the hippocampus of AD model rats was significantly increased, while CPCGI significantly decreased the mRNA expression of $A \beta 40$ and $A \beta 42$ (Fig. 2B and C). Compared with the rats from the sham group, the production of TNF- $\alpha$ and IL-1 $\beta$ in the hippocampus of AD model rats was significantly increased, and these increases were inhibited by CPCGI treatment (Fig. 2D and E). In addition, the content of MDA in the hippocampus of $A \beta 1-42$ induced rats was significantly increased (Fig. 2F), the activity of SOD was significantly decreased (Fig. 2G), and the ROS level significantly enhanced (Fig. 2H). CPCGI treatment significantly reduced the content of MDA, increased the activity of SOD, and decreased ROS level in the hippocampus of AD model rats (Fig. 2F-H). 
A

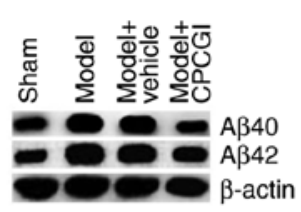

B
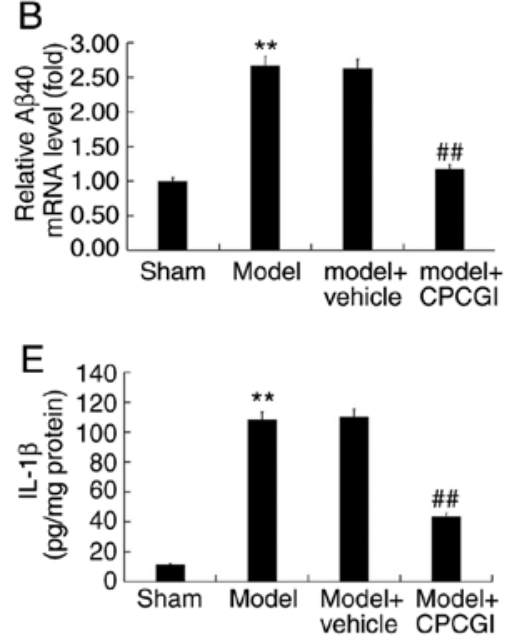

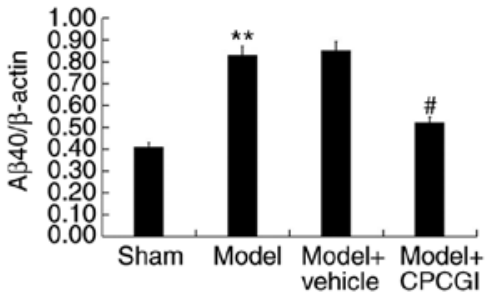

C
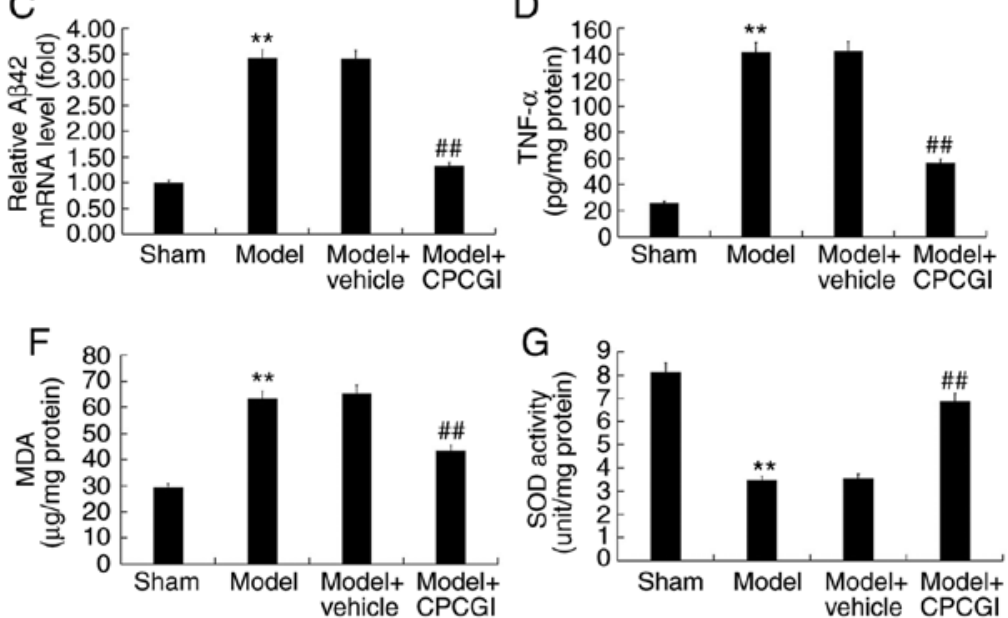

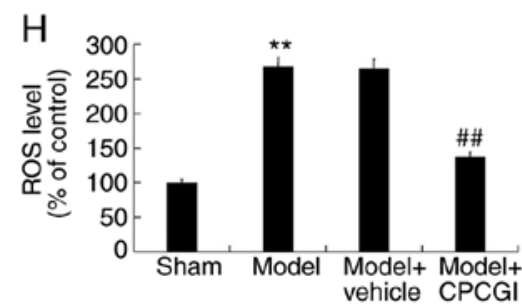

Figure 2. Effect of CPCGI on AD rat model. (A) Western blot assay was used to detect the protein expression of $\mathrm{A} \beta 40$ and $\mathrm{A} \beta 42$ in the hippocampus of $\mathrm{AD}$ rats treated with or without CPCGI, and A $\beta 40 / \beta$-actin and A $\beta 42 / \beta$-actin was calculated and presented. (B and C) RT-qPCR was used to detect the mRNA expression of $A \beta 40$ and $A \beta 42$ in the hippocampus of $A D$ rats treated with or without CPCGI. (D and E) ELISA was used to detect the levels of inflammatory cytokines TNF- $\alpha$ and IL-1 $\beta$ in the hippocampus of AD rats treated with or without CPCGI. The effect of CPCGI on (F) MDA secretion, (G) SOD activity and (H) ROS production. Experiments were repeated three times. Data are given as the mean \pm standard deviation. ${ }^{* *} \mathrm{P}<0.01$ vs. the sham group; ${ }^{\sharp} \mathrm{P}<0.05$ vs. the model group; ${ }^{\#} \mathrm{P}<0.01$ vs. the model group. CPCGI, compound porcine cerebroside and ganglioside injection; AD, Alzheimer's disease; A $\beta$, amyloid- $\beta$; RT-qPCR, reverse transcription-quantitative PCR; TNF, tumor necrosis factor; IL, interleukin; MDA, malondialdehyde; SOD, superoxide dismutase; ROS, reactive oxygen species.

A

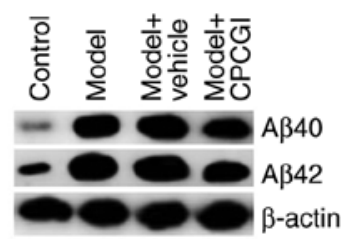

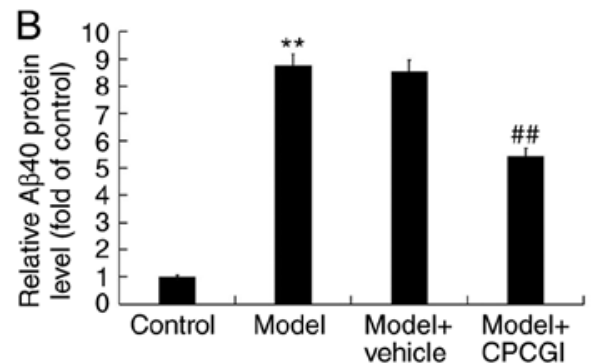

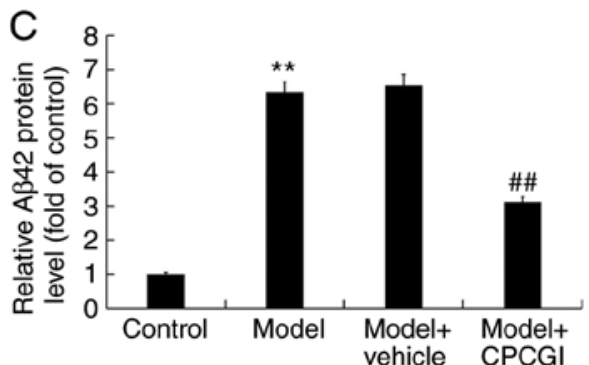

Figure 3. Effect of CPCGI on A $\beta$ accumulation in AD PC12 cell model. (A) Western blotting was used to detect the protein expression of (B) A 340 and (C) A 42 of AD PC12 cells treated with or without CPCGI. Experiments were repeated three times. Data were given as the mean \pm standard deviation. ${ }^{* *} \mathrm{P}<0.01$ vs. the control group; ${ }^{\# \#} \mathrm{P}<0.01$ vs. the model group. $\mathrm{CPCGI}$, compound porcine cerebroside and ganglioside injection; $\mathrm{A} \beta$, amyloid- $\beta$; $\mathrm{AD}$, Alzheimer's disease.

$C P C G I$ reduced the protein expression of $A \beta 40$ and $A \beta 42$ in $A \beta 25-35$ induced PC12 cells. In order to detect the protein expression of $A \beta 40$ and $A \beta 42$, western blot analysis was used. The results demonstrated that the protein expression of $A \beta 40$ and $A \beta 42$ in $A \beta 25-35$ induced PC12 cells increased significantly compared with the control group, and that CPCGI could decrease the protein expression of $A \beta 40$ and $A \beta 42$ in $A \beta 25-35$ induced $\mathrm{PC} 12$ cells (Fig. 3A-C).

CPCGI enhanced the viability of A $\beta 25-35$ induced PC12 cells. MTT assay was used to investigate the effect of CPCGI on the viability of $\mathrm{PC} 12$ cells. The results demonstrated that compared with the control group, the viability of PC12 cells was significantly 

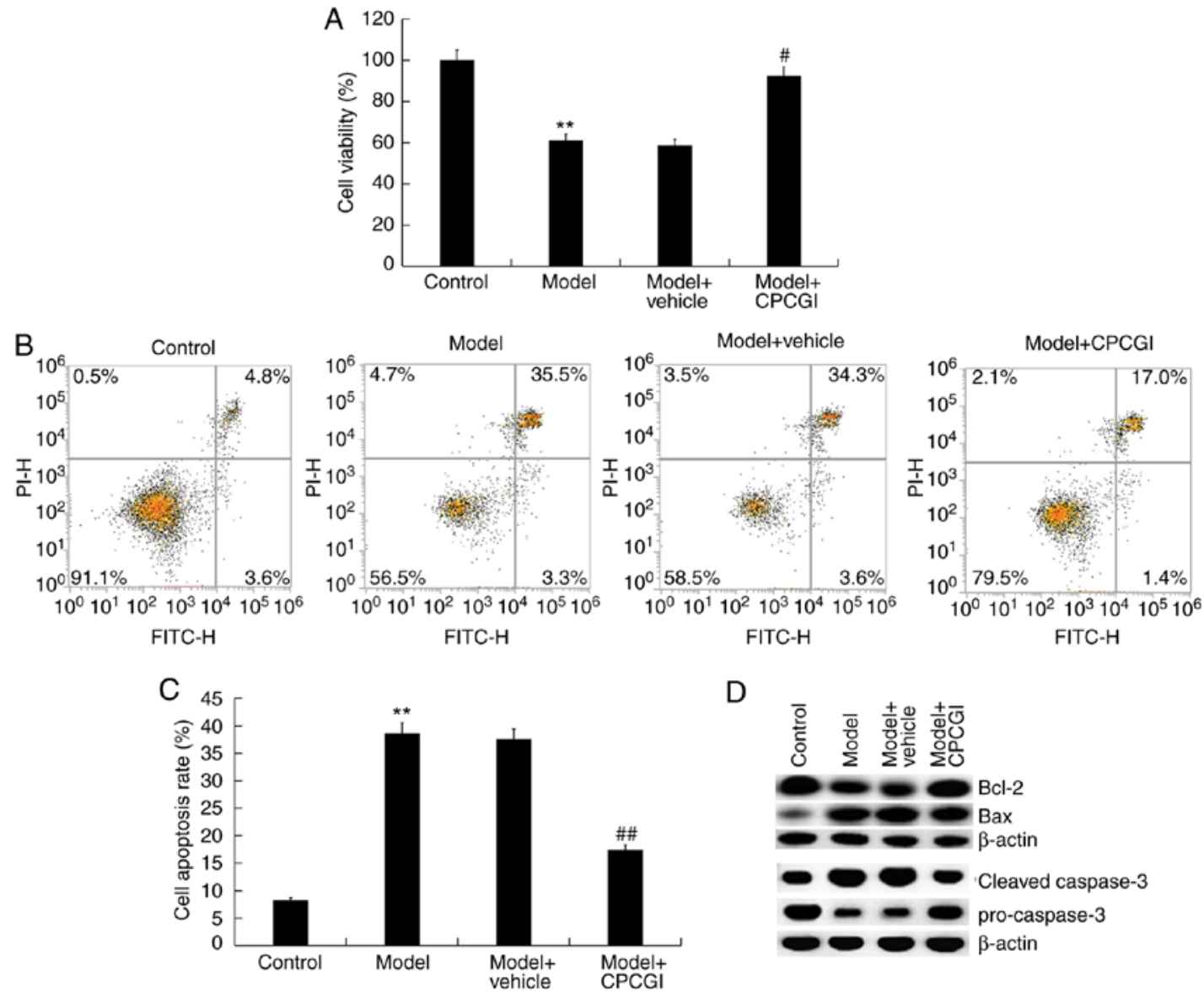

D
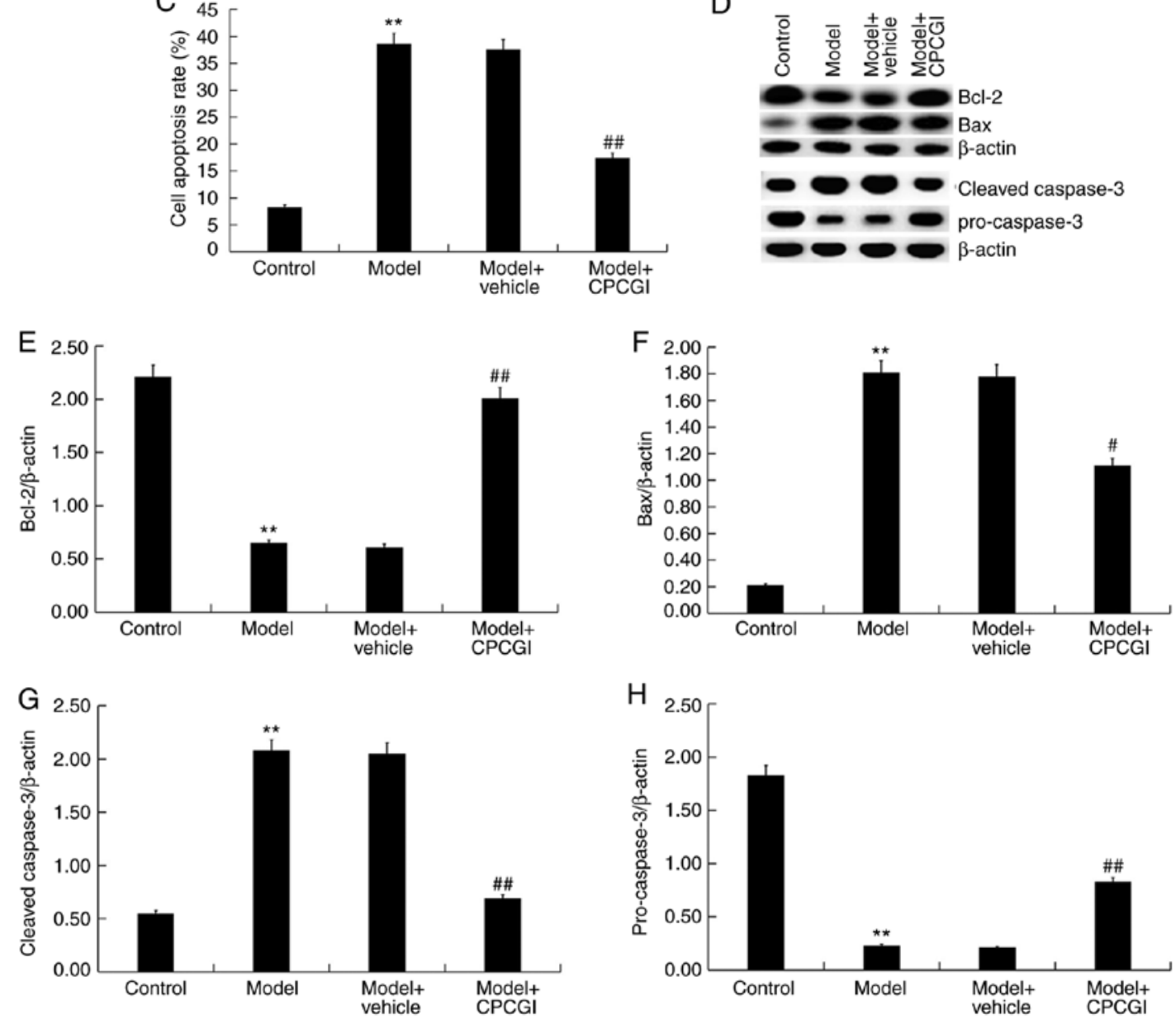

Figure 4. Effect of CPCGI on cell viability and apoptosis of AD PC12 cells. (A) MTT analysis was used to detect the viability of AD PC12 cells treated with or without CPCGI. (B and C) Flow cytometry was used to detect apoptosis in AD PC12 cells treated with or without CPCGI. (D) Western blotting was used to detect the expression of Bcl2, Bax, cleaved-caspase3, and pro-caspase3 protein in AD PC12 cells treated with or without CPCGI. The ratio of (E) Bcl2/ $\beta$-actin, (F) Bax/ $\beta$-actin, (G) cleaved-caspase3/ $/ \beta$-actin and (H) pro-caspase3/ $\beta$-actin was calculated and presented. Experiments were repeated three times. Data are given as the mean \pm standard deviation. ${ }^{* *} \mathrm{P}<0.01$ vs. the control group; ${ }^{\#} \mathrm{P}<0.05$ vs. the model group; ${ }^{* \#} \mathrm{P}<0.01$ vs. the model group. CPCGI, compound porcine cerebroside and ganglioside injection; $\mathrm{AD}$, Alzheimer's disease.

decreased in A $\beta 25-35$ treated PC12 cells. CPCGI treatment could significantly increase the viability of $A \beta 25-35$ induced PC12 cells (Fig. 4A).
CPCGI reduced apoptosis of A $\beta 25-35$ induced PC12 cells. Flow cytometry was used to analyze the effect of CPCGI on apoptosis in PC12 cells. Compared with the control 

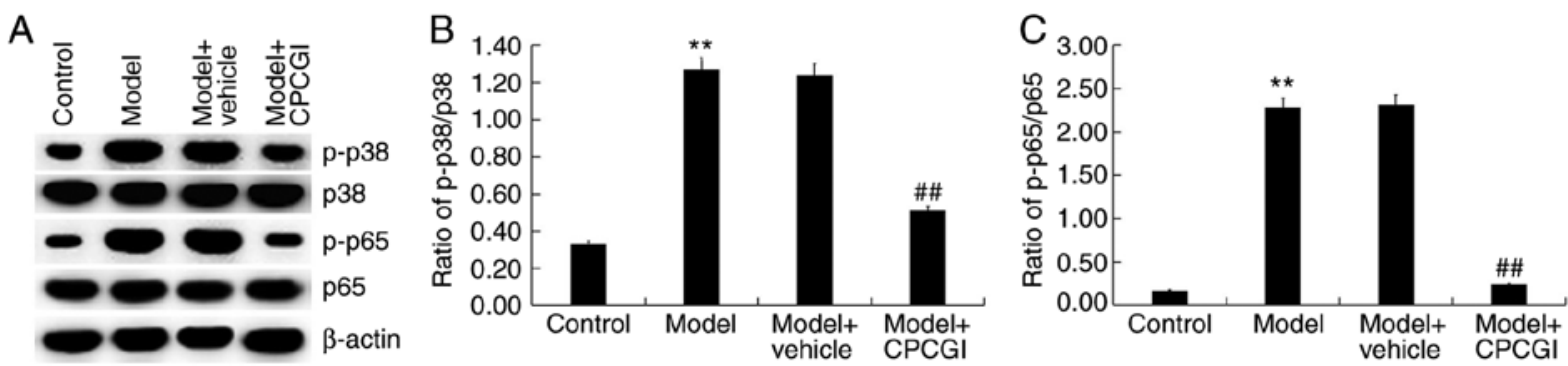

Figure 5. Effect of CPCGI on MAPK/NF-kB pathway in AD PC12 cell model. (A) Western blot assay was used to detect the expression of p38, p65, p-p38, p-p65 and $\beta$-actin in PC12 cells treated with or without CPCGI. The ratio of (B) p-p38/p38 and (C) p-p65/p65 was calculated and presented. Experiments were repeated three times. Data are given as the mean \pm standard deviation. ${ }^{* *} \mathrm{P}<0.01$ vs. the control group; ${ }^{\# \#} \mathrm{P}<0.01$ vs. the model group. CPCGI, compound porcine cerebroside and ganglioside injection; MAPK, mitogen-activated protein kinase.

group, the apoptosis of PC12 cells in AD cell model group increased significantly. The apoptosis of $\mathrm{A} \beta 25-35$ induced PC12 cells (Fig. 4B and C) was significantly reduced by CPCGI treatment. In addition, the protein expression of Bcl2 (Fig. 4D and E) and pro-caspase 3 decreased (Fig. 4D and $\mathrm{H}$ ), while the protein level of Bax (Fig. 4D and F) and cleaved-caspase3 (Fig. 4D and G) increased significantly in A $325-35$ induced $\mathrm{PC} 12$ cells, and these changes were inhibited by CPCGI treatment (Fig. 4D-H).

CPCGI reduced p-p38 and p-p65 expression in A $\beta 25-35$ induced PC12 cells. To explore the mechanism by which CPCGI affected $\mathrm{AD}$, the $\mathrm{p} 38$ mitogen-activated protein kinase (MAPK)/NF- $\kappa B$ pathway was analyzed. In addition, the protein expression of p38, p65, p-p38 and p-p65 in PC12 cells was detected using western blot analysis. The results demonstrated that the protein expression of p-p38 and p-p65 and the ratio of p-p38/p38 and p-p65/p65 in A $325-35$ induced $\mathrm{PC} 12$ cells were significantly higher than that in the control group. CPCGI treatment significantly reduced the protein expression of p-p38 and p-p65 and the ratio of p-p38/p38 and p-p65/p65 in $\mathrm{A} \beta 25-35$ induced $\mathrm{PC} 12$ cells (Fig. $5 \mathrm{~A}-\mathrm{C}$ ), indicating the inhibitory effect of CPCGI on p38MAPK/NF- $\mathrm{KB}$ pathway in A $\beta 25-35$ induced PC12 cells.

\section{Discussion}

Alzheimer's disease is a degenerative disease of the central nervous system characterized by progressive memory impairment and mental retardation $(1,5)$. With the aging of the world population, the incidence of Alzheimer's disease is increasing, therefore, it is urgent to find new and effective methods for treating AD. In recent years, a great deal of research has been performed on the etiology and pathogenesis of Alzheimer's disease $(23,24)$. A $\beta$ (6-8), inflammatory factors (25) and oxidative stress markers MDA and SOD $(26,27)$ have been found to serve a leading role in the occurrence and development of AD. Previous studies have found that folic acid could improve learning and memory in rats with $\mathrm{AD}$ by directly or indirectly inhibiting or clearing the deposition of $A \beta$ in the hippocampus and olfactory region (28-30). In addition, zuo-gui pills, a classic TCM formulation $(31,32)$, can effectively increase the activity of SOD and decrease the content of MDA in brain tissue of AD model rats (33). In the study of CPCGI, a previous study found that CPCGI has a neuroprotective effect on middle cerebral artery occlusion injured rats by inhibiting apoptosis and improving synaptic and mitochondrial function (10). In a study of the protective effect of CPCGI on cerebral ischemia-reperfusion injury in rats, the results suggested that one of the neuroprotective mechanisms of CPCGI may be related to activation of mitochondrial autophagy and improvement of mitochondrial function (15).

Previous studies have demonstrated that CPCGI has neuroprotective effect $(10,11,15)$, but its neuroprotective mechanism for $\mathrm{AD}$ is still unclear, therefore, the present study investigated the effect of CPCGI on AD. In the present study, the rat model of $\mathrm{AD}$ was established using $\mathrm{A} \beta 1-42$ and then treated with CPCGI. Depression is prevalent in patients with AD $(34,35)$. Previous studies have revealed that intracerebroventricular or hippocampal injection of A $1-42$ results in depressive-like symptoms in rats (36-39). Therefore, the present study determined the effect of CPCGI on the percentage of sucrose preference and the immobility time of rats with $\mathrm{AD}$, and found that CPCGI significantly enhanced the percentage of sucrose preference of $\mathrm{AD}$ rats and reduced the immobility time of rats treated with A $31-42$. Each ml of CPCGI contains $0.24 \mathrm{mg}$ Monosialotetrahexosyl ganglioside (GM-1), $3.2 \mathrm{mg}$ of polypeptides, and $0.125 \mathrm{mg}$ of hypoxanthine $(10,11)$. As GM-1 $(40,41)$ and polypeptides (42) all have been reported to have neuroprotective effects, it was hypothesized that CPCGI may serve a protective role in AD mainly through GM-1 and polypeptides, however, this need further research.

The protein expression of $A \beta 40$ and $A \beta 42$, inflammatory factors TNF- $\alpha$ and IL- $1 \beta$, the MDA secretion and SOD activity associated with oxidative stress markers, and ROS production, which are involved in the occurrence and development of $\mathrm{AD}$, were identified in the hippocampus of AD model rats. The findings indicated that CPCGI administration significantly decreased the protein expression of $A \beta 40$ and $A \beta 42$, and that the production of TNF- $\alpha$ and IL-1 $\beta$ in the hippocampus of AD model rats was also reduced by CPCGI treatment. CPCGI treatment significantly reduced the MDA content, increased SOD activity and reduced ROS level in the hippocampus of $\mathrm{AD}$ model rats. However, as the detection of injected $\mathrm{A} \beta$ may be controversial because of the detected expression could be due to the injected $A \beta$, the expression of injected $A \beta$ in rats or PC12 cells were not measured in the present study.

An in vitro model of $\mathrm{AD}$ was established by subjecting PC12 cells to A $\beta 25-35$, and it was found that the viability of AD model cells significantly decreased and the apoptosis of cells increased. The results of the current study were consistent 
with previous studies $(43,44)$ : CPCGI treatment significantly enhanced the viability of PC12 cells induced by A $\beta 25-35$ and reduced cell apoptosis.

The MAPK/NF- $\kappa$ B pathway, serves important roles in the regulation of cell growth and inflammatory response, and has been revealed to be activated during the development of AD $(45,46)$. Thus, to explore the mechanism by which CPCGI affected $\mathrm{AD}$, the $\mathrm{p} 38 \mathrm{MAPK} / \mathrm{NF}-\kappa \mathrm{B}$ pathway was analyzed. As expected, it was observed that the activated $\mathrm{p} 38 \mathrm{MAPK} / \mathrm{NF}-\kappa \mathrm{B}$ pathway caused by $A \beta 25-35$ induction was inhibited by CPCGI treatment.

In conclusion, the results of the present study suggested that CPCGI served a protective role in AD development by reducing $A \beta$ accumulation, inhibiting inflammatory response and oxidative stress, and preventing neuronal apoptosis by inhibiting MAPK/NF- $\mathrm{B}$ signaling pathway activation. However, the present study is a preliminary study of the role of CPCGI in AD, and has some limitations. For example, the pathological changes of $\mathrm{AD}$ rats were not analyzed using microscopy. The p38MAPK/NF- $\kappa$ B pathway was not analyzed in vivo. A group of p38 specific inhibitor or $\mathrm{NF}-\kappa \mathrm{B}$ specific inhibitor combination therapies was not conducted in the present study nor did it investigate the effect of CPCG1 on normal rats and PC12 cells. In order to make the role of CPCGI in AD more convincing, more research is needed. For instance, whether CPCGI serves a role in AD by directly affecting p38MAPK and $\mathrm{NF}-\kappa \mathrm{B}$ signaling in vivo and in vitro should be investigated. In addition, the effect of CPCGI on normal rats and normal PC12 cells should be studied.

\section{Acknowledgements}

Not applicable.

\section{Funding}

No funding was received.

\section{Availability of data and materials}

All datasets used and/or analyzed during the current study are available from the corresponding author on reasonable request.

\section{Authors' contributions}

XW performed study design, data collection, statistical analysis, data interpretation and manuscript preparation. JZ performed data collection and statistical analysis.

\section{Ethics approval and consent to participate}

The present study was performed according to the principles and procedures of the National Institutes of Health's Guide for the Care and Use of Laboratory Animals. This study was approved by the Animal Care and Use Committee of the Second Hospital of Hebei Medical University.

\section{Patient consent for publication}

Not applicable.

\section{Competing interests}

The authors declare that they have no competing interests.

\section{References}

1. Selkoe DJ: Alzheimer's disease: Genes, proteins, and therapy. Physiol Rev 81: 741-766, 2001.

2. Dubois B, Feldman HH, Jacova C, Dekosky ST, BarbergerGateau P, Cummings J, Delacourte A, Galasko D, Gauthier S, Jicha G, et al: Research criteria for the diagnosis of Alzheimer's disease: Revising the NINCDS-ADRDA criteria. Lancet Neurol 6: 734-746, 2007.

3. Kang J, Lemaire HG, Unterbeck A, Salbaum JM, Masters CL, Grzeschik KH, Multhaup G, Beyreuther K and Müller-Hill B: The precursor of Alzheimer's disease amyloid A4 protein resembles a cell-surface receptor. Nature 325: 733-736, 1987.

4. Glenner GG and Wong CW: Alzheimer's disease: Initial report of the purification and characterization of a novel cerebrovascular amyloid protein. Biochem Biophys Res Commun 120: 885-890, 1984.

5. Lane CA, Hardy J and Schott JM: Alzheimer's disease. Eur J Neurol 25: 59-70, 2018.

6. Frost PS, Barros-Aragão F, da Silva RT, Venancio A, Matias I, Lyra E Silva NM, Kincheski GC, Pimentel-Coelho PM, De Felice FG, Gomes FCA, et al: Neonatal infection leads to increased susceptibility to $\mathrm{A} \beta$ oligomer-induced brain inflammation, synapse loss and cognitive impairment in mice. Cell Death Dis 10: 323, 2019.

7. Blennow K, Leon MJD and Zetterberg H: Alzheimer's disease. Lancet 368: 387-403, 2006.

8. Ballard C, Gauthier S, Corbett A, Brayne C, Aarsland D and Jones E: Alzheimer's disease. Lancet 377: 1019-1031, 2011.

9. Teng E, Taylor K, Bilousova T, Weiland D, Pham T, Zuo X, Yang F, Chen PP, Glabe CG, Takacs A, et al: Dietary DHA supplementation in an APP/PS1 transgenic rat model of AD reduces behavioral and $A \beta$ pathology and modulates $A \beta$ oligomerization. Neurobiol Dis 552-560, 2015.

10. Wang M, Zhang Y, Feng L, Zheng J, Fan S, Liu J, Yang N, Liu Y and Zuo P: Compound porcine cerebroside and ganglioside injection attenuates cerebral ischemia-reperfusion injury in rats by targeting multiple cellular processes. Neuropsychiatr Dis Treat 13: 927-935, 2017.

11. Wang M, Feng L, Fan S, Zheng JI, LI DM, Yang N, Zuo P and Liu Y: Effect of Compound porcine cerebroside and ganglioside injection on cerebral ischemia-reperfusion injury in rats. Chin J Rehabil Theory Prac: 281-285, 2016.

12. Kwak DH, Kim SM, Lee DH, Kim JS, Kim SM, Lee SU, Jung KY, Seo BB and Choo YK: Differential expression patterns of gangliosides in the ischemic cerebral cortex produced by middle cerebral artery occlusion. Mol Cells 20: 354-360, 2005.

13. Zamfir AD: Neurological analyses: Focus on gangliosides and mass spectrometry. Adv Exp Med Biol 806: 153-204, 2014.

14. Huang XF, Wang JM, Chen Q, Wei YY and Chen HW: Meta-analysis on effect of compound Danshen injection in treating neonatal hypoxic-ischemic encephalopathy. Zhongguo Zhong Yao Za Zhi 40: 141-148, 2015 (In Chinese)

15. Wang H, Jiang HQ, Li J, et al: Clinical study of Compound Porcine Cerebroside and Ganglioside Injection on Alzheimer disease. Chinese Community doctors 12: 127-128, 2010 (In Chinese).

16. Bayne K: Revised guide for the care and use of laboratory animals available. American physiological society. Physiologist 39: 199, 208-211, 1996.

17. Amani M, Shokouhi G and Salari AA: Minocycline prevents the development of depression-like behavior and hippocampal inflammation in a rat model of Alzheimer's disease. Psychopharmacology (Berl) 236: 1281-1292, 2018.

18. Garcez ML, Mina F, Bellettini-Santos T, Carneiro FG, Luz AP, Schiavo GL, Andrighetti MS, Scheid MG, Bolfe RP and Budni J: Minocycline reduces inflammatory parameters in the brain structures and serum and reverses memory impairment caused by the administration of amyloid $\beta$ (1-42) in mice. Prog Neuropsychopharmacology Biol Psychiatry 77: 23-31, 2017.

19. Cioanca O, Hritcu L, Mihasan M, Trifan A and Hancianu M: Inhalation of coriander volatile oil increased anxiolytic-antidepressant-like behaviors and decreased oxidative status in beta-amyloid (1-42) rat model of Alzheimer's disease. Physiol Behav 131: 68-74, 2014. 
20. Sharifi AM and Mousavi SH: Studying the effects of lead on DNA fragmentation and proapoptotic bax and antiapoptotic Bcl-2 protein expression in PC12 cells. Toxicol Mech Methods 18: 55-79, 2008.

21. Lee S, Youn K, Kim DH, Ahn MR, Yoon E, Kim OY and Jun M: Anti-neuroinflammatory property of phlorotannins from Ecklonia cava on $\mathrm{A} \beta_{25-35}$-induced damage in PC12 cells. Mar Drugs 17: E7, 2018.

22. Livak KJ and Schmittgen TD: Analysis of relative gene expression data using real-time quantitative PCR and the 2(-Delta Delta C(T)) method. Methods 25: 402-408, 2001.

23. Balin BJ and Hudson AP: Etiology and pathogenesis of late-onset Alzheimer's disease. Curr Allergy Asthma Rep 14: 417, 2014.

24. Area-GomezE and Schon EA: On the pathogenesis of Alzheimer's disease: The MAM hypothesis. FASEB J 31: 864-867, 2017.

25. Bolós M, Perea JR and Avila J: Alzheimer's disease as an inflammatory disease. Biomol Concepts 8: 37-43, 2017.

26. Nazıroğlu M, Muhamad S and Pecze L: Nanoparticles as potential clinical therapeutic agents in Alzheimer's disease: Focus on selenium nanoparticles. Expert Rev Clin Pharmacol 10: 773-782, 2017.

27. Dastan Z, Pouramir M, Ghasemi-Kasman M, Ghasemzadeh Z, Dadgar M, Gol M, Ashrafpour M, Pourghasem M, Moghadamnia AA and Khafri S: Arbutin reduces cognitive deficit and oxidative stress in animal model of Alzheimer's disease. Int J Neurosci 129: 1145-1153, 2019.

28. Faux NG, Ellis KA, Porter L, Fowler CJ, Laws SM, Martins RN, Pertile KK, Rembach A, Rowe CC, Rumble RL, et al: Homocysteine, vitamin B12, and folic acid levels in Alzheimer's disease, mild cognitive impairment, and healthy elderly: Baseline characteristics in subjects of the Australian imaging biomarker lifestyle study. J Alzheimers Dis 27: 909-922, 2011.

29. Connelly PJ, Prentice NP, Cousland G and Bonham J: A randomised double-blind placebo-controlled trial of folic acid supplementation of cholinesterase inhibitors in Alzheimer's disease. Int J Geriatr Psychiatry 23: 155-160, 2010.

30. Chen H, Liu S, Ji L, Wu T, Ji Y, Zhou Y, Zheng M, Zhang M, $\mathrm{Xu} \mathrm{W}$ and Huang G: Folic acid supplementation mitigates Alzheimer's disease by reducing inflammation: A randomized controlled trial. Mediators Inflamm 2016: 5912146, 2016.

31. Kou S, Zheng Q, Wang Y, Zhao H, Zhang Q, Li M, Qi F, Fang L, Liu L, Ouyang J, et al: Zuo-Gui and You-Gui pills, two traditional Chinese herbal formulas, downregulated the expression of NogoA, $\mathrm{NgR}$, and RhoA in rats with experimental autoimmune encephalomyelitis. J Ethnopharmacol 158: 102-112, 2014.

32. Wang YZ, Kou S, Gu LY, Zheng Q, Li M, Qi F, Zhao H and Wang L: Effects of Zuogui Pill () and Yougui Pill () on the expression of brain-derived neurotrophic factor and cyclic adenosine monophosphate/protein kinase A signaling transduction pathways of axonal regeneration in model rats with experimental autoimmune encephalomyelitis. Chin J Integr Med 20: 24-30, 2014.

33. Bracegirdle S: The effects of Zuo-gui pills on SOD and MDA of AD model mice. Chin Arch Tradit Chin Med: 2583-2585, 2010 (In Chinese).

34. Engedal K, Barca ML, Laks J and Selbaek G: Depression in Alzheimer's disease: Specificity of depressive symptoms using three different clinical criteria. Int J Geriatr Psychiatry 26: 944-951, 2011

35. Benoit M, Berrut G, Doussaint J, Bakchine S, Bonin-Guillaume S, Frémont $\mathrm{P}$, Gallarda $\mathrm{T}$, Krolak-Salmon $\mathrm{P}$, Marquet $\mathrm{T}$, Mékiès $\mathrm{C}$, et al: Apathy and depression in mild Alzheimer's disease: A cross-sectional study using diagnostic criteria. J Alzheimers Dis 31: 325-334, 2012.
36. Souza LC, Jesse CR, Del Fabbro L, de Gomes MG, Goes ATR, Filho CB, Luchese C, Pereira AAM and Boeira SP: Swimming exercise prevents behavioural disturbances induced by an intracerebroventricular injection of amyloid- $\beta_{1-42}$ peptide through modulation of cytokine/NF-kappaB pathway and indoleamine-2,3-dioxygenase in mouse brain. Behav Brain Res 331: $1-13,2017$.

37. Souza LC, Jesse CR, Antunes MS, Ruff JR, de Oliveira Espinosa D, Gomes NS, Donato F, Giacomeli R and Boeira SP: Indoleamine-2,3-dioxygenase mediates neurobehavioral alterations induced by an intracerebroventricular injection of amyloid- $\beta 1-42$ peptide in mice. Brain Behav Immun 56: 363-377, 2016.

38. Guo J, Chang L, Li C, Li M, Yan P, Guo Z, Wang C, Zha Q and Wang Q: Sb203580 reverses memory deficits and depression-like behavior induced by microinjection of $\mathrm{A} \beta_{1-42}$ into hippocampus of mice. Metab Brain Dis 32: 57-68, 2017.

39. Song X, Liu B, Cui L, Zhou B, Liu W, Xu F, Hayashi T, Hattori S, Ushiki-Kaku Y, Tashiro SI and Ikejima T: Silibinin ameliorates anxiety/depression-like behaviors in amyloid $\beta$-treated rats by upregulating BDNF/TrkB pathway and attenuating autophagy in hippocampus. Physiol Behav 179: 487-493, 2017.

40. Dai R, Zhang S, Duan W, Wei R, Chen H, Cai W, Yang L and Wang Q: Enhanced autophagy contributes to protective effects of GM1 ganglioside against A $31-42$-induced neurotoxicity and cognitive deficits. Neurochem Res 42: 2417-2426, 2017.

41. Gong G, Yin L, Yuan L, Sui D, Sun Y, Fu H, Chen L and Wang X: Ganglioside GM1 protects against high altitude cerebral edema in rats by suppressing the oxidative stress and inflammatory response via the PI3K/AKT-Nrf2 pathway. Mol Immunol 95: 91-98, 2018

42. Jin W, Xu X, Chen X, Qi W, Lu J, Yan X, Zhao D, Cong D, Li X and Sun L: Protective effect of pig brain polypeptides against corticosterone-induced oxidative stress, inflammatory response, and apoptosis in PC12 cells. Biomed Pharmacother 115: 108890, 2019.

43. Zeng Z, Xu J and Zheng W: Artemisinin protects PC12 cells against $\beta$-amyloid-induced apoptosis through activation of the ERK1/2 signaling pathway. Redox Biol 12: 625-633, 2017.

44. Wang YL, Wang ZW and Song W: Set up Alzheimer's disease cell apoptosis model with PC-12 cell induced by $\mathrm{A} \beta(25-35)$ J Nanjing Med Univ 208-214, 2003 (In Chinese).

45. Lee S, Youn K and Jun M: Major compounds of red ginseng oil attenuate $A \beta_{25-35}$-induced neuronal apoptosis and inflammation by modulating MAPK/NF- $\kappa$ B pathway. Food Funct 9: 4122-4134, 2018.

46. Liu H, Deng Y, Gao J, Liu Y, Li W, Shi J and Gong Q: Sodium hydrosulfide attenuates beta-amyloid-induced cognitive deficits and neuroinflammation via modulation of MAPK/NF- $\mathrm{BB}$ pathway in rats. Curr Alzheimer Res 12: 673-683, 2015.

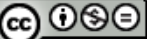

This work is licensed under a Creative Commons Attribution-NonCommercial-NoDerivatives 4.0 International (CC BY-NC-ND 4.0) License. 